\title{
Immunogenicity and safety of PRP-T conjugate vaccine given according to the British accelerated immunisation schedule
}

\author{
R Booy, S A Taylor, S R M Dobson, D Isaacs, G Sleight, S Aitken, H Griffiths, \\ H Chapel, R T Mayon-White, J A Macfarlane, E R Moxon
}

\begin{abstract}
The immunogenicity and safety of a new Haemophilus influenzae type b conjugate vaccine, PRP-T, was studied in 107 infants from the Oxford district. The vaccine was given concurrently with diphtheria, pertussis, tetanus, and polio vaccines at 2,3 , and 4 months of age. Symptoms after immunisation were recorded by a parent. Sera were obtained before the first immunisation and at 5 months of age and the antibodies were measured by both radioimmunoassay and enzyme linked immunosorbent assay (ELISA). No serious adverse reactions were observed and there was no increase in the incidence of expected minor side effects. By radioimmunoassay, the geometric mean titre of serum anticapsular antibody increased from $0.09 \mu \mathrm{g} / \mathrm{ml}$ before immunisation to $5.01 \mu \mathrm{g} / \mathrm{ml}$ after three immunisations. Ninety eight per cent of children had antibody concentrations consistent with protection $(\geqslant 0 \cdot 15 \mu \mathrm{g} / \mathrm{ml})$. IgG antibody concentrations measured by ELISA correlated well with total antibody concentrations measured by radioimmunoassay $(r=0.864)$. These results provide encouragement that routine immunisation against $H$ influenzae type b at 2, 3, and 4 months of age, could prevent most cases of disease in children in the UK.
\end{abstract}

John Radcliffe Hospital, Oxford, University Department of Paediatrics

R Booy

$S$ A Taylor

S R M Dobson

$D$ Isaacs

E R Moxon

Department of

Immunology

S Aitken

H Griffiths

H Chapel

Department of

Public Health

R T Mayon-White

Department of

Community Health,

Radcliffe Infirmary,

Oxford

G Sleight

J A Macfarlane

Correspondence to: Dr R Booy, Department of Paediatrics, John Radcliffe Hospital, Headington

Oxford OX3 9DU.

Accepted 11 December 1991 with absent or low concentrations of serum antibodies to PRP, a finding that is typical of infants in their first and second years. ${ }^{5}$ Enhancement of the immunoprotective response to polysaccharide antigen is possible through its covalent linkage (conjugation) to a carrier protein, ${ }^{6}$ which results in $\mathrm{T}$ cell dependency and a boostable response, thereby offering the potential of antibody responses that would protect young infants. Four conjugate vaccines against $H$ influenzae type b have been developed, conjugates of PRP respectively to diphtheria toxoid (PRP-D), tetanus toxoid (PRP-T), a diphtheria toxin mutant (HbOC), and an outer membrane protein of meningococcus (PRP-OMP).

Immunogenicity studies comparing these conjugate vaccines given according to current Finnish and American primary immunisation schedules (Finnish: 4 and 6 months of age; USA 2, 4, and 6 months of age), suggest that PRP-T is at least as immunogenic as other conjugate vaccines and it has been shown to result in a greater antibody response after one or two injections than PRP-D or HbOC. ${ }^{78}$ Also, the booster response to PRP-T is significantly greater than that seen with PRP-OMP. ${ }^{8}$ Thus PRP-T appears an acceptable candidate for inclusion in the British schedule of immunisation at 2, 3, and 4 months of age.

Routine immunisation against $H$ influenzae type $b$ of infants under 6 months of age has become part of the routine primary schedule in the USA and several European countries. ${ }^{9}$ The Department of Health has indicated that the UK will implement routine immunisation in October 1992. It has been shown previously that the conjugate vaccine $\mathrm{HbOC}$ is highly immunogenic in UK infants using the primary schedule of 3,5 , and 9 months, ${ }^{10}$ but in May 1990 the primary schedule in the UK was altered to 2, 3, and 4 months of age. The purpose of this study was to determine the safety and immunogenicity of the conjugate vaccine PRP-T when given concurrently with diphtheria, pertussis, tetanus, and polio vaccines and according to the accelerated schedule of primary immunisation at 2,3, and 4 months of age. Antibody concentrations to PRP were measured by both radioimmunoassay and enzyme linked immunosorbent asasy (ELISA) as part of the validation of the ELISA used.

Patients and methods

One hundred and seven Oxfordshire infants were recruited over a two month period. Parents were approached on the second or subsequent 
days after birth with information about the study. Written consent was not requested until the child was at least 6 weeks of age. Seventy five per cent of those invited agreed to take part. Infants were randomised to receive one of three batches of PRP-T (Pasteur Merieux Serum et Vaccins; batch numbers S2141, S2181, S2189). PRP-T is a freeze dried lyophilised conjugate vaccine which is reconstituted with $0.5 \mathrm{ml}$ sodium chloride $0 \cdot 4 \%$. Immunisations took place in the family home at 2,3 , and 4 months of age. $H$ influenzae type $\mathrm{b}$ vaccine was given by intramuscular injection in the right thigh and, at the same visit, diphtheria, pertussis, and tetanus vaccine (Wellcome) was given in the left thigh. Oral polio vaccine was also administered. Blood for serology was obtained at the first visit and again one month after completing the primary series. Blood samples were separated on the day of venepuncture and serum stored in $0.5 \mathrm{ml}$ aliquots at $-20^{\circ} \mathrm{C}$ until required.

Parents were given a form to document any symptoms in the three days after each immunisation. They recorded axillary temperatures daily and at any other time if the infant felt hot. The size of local redness or swelling was measured with a calliper. Parents were taught how to use a thermometer and the calliper and were telephoned within one to three days of immunisation to check on progress. They were not told the side on which a particular injection was given, so infants acted as their own control for local reactions.

Total anti-PRP antibodies were measured using Farr type radioimmunoassay ${ }^{11}$ by $\mathrm{Dr} \mathrm{H}$ Kayhty and L Saarinen at the National Public Health Institute in Finland with the standard reference serum from the Food and Drug Administration, USA (72 $\mu \mathrm{g}$ per $\mathrm{ml}$ ).

IgG antibodies to PRP were measured in Oxford by an ELISA using a modification of the method described by Kumararatne et al. ${ }^{12}$ All incubations were at room temperature for one hour unless otherwise stated and were followed by four washes with phosphate buffered saline plus $0.05 \%$ Tween 20 (PBS-T). PRP (provided by Pasteur-Merieux Serum et Vaccins, France) was covalently bound to poly-L-lysine ${ }^{13}$ and diluted in $0.05 \mathrm{M}$ carbonate buffer ( $\mathrm{pH} \mathrm{9.6)}$ to approximately $1 \mu \mathrm{g} / \mathrm{ml}$. This solution was added to flat bottomed microtitre plates (Immulon 1, Dynatech) using $100 \mu \mathrm{l}$ per well and incubated overnight at $4^{\circ} \mathrm{C}$. Aliquots of $100 \mu \mathrm{l}$ of test or standard sera diluted in PBS-T were added to each well. After incubation, the wells were exposed to mouse antihuman IgG diluted in PBS-T, followed. by peroxidase conjugated sheep antimouse IgG diluted in PBS-T and finally to substrate solution $(0.4 \mathrm{mg} / \mathrm{ml} \mathrm{o-}$ phenylenediamine dihydrochloride in $0.15 \mathrm{M}$ citrate phosphate buffer, pH 5 with $1 \mu l$ hydrogen peroxide per $5 \mathrm{ml}$ substrate solution). The colour was allowed to develop in the dark and the reaction was stopped after 30 minutes by the addition of $25 \mu \mathrm{l} 10 \%$ sulphuric acid. The optical density was measured at $492 \mathrm{~nm}$ using a Multiscan ELISA reader. A log linear standard curve was plotted with antibody concentration against optical density, from which the antibody concentration of the test samples could be calculated. The lower limit of sensitivity of the assay was $0 \cdot 16 \mu \mathrm{g} / \mathrm{ml}$. A standard reference serum was obtained from Dr $\mathrm{H}$ Kayhty in Finland. Both the Oxford and Finnish laboratories take part in the European quality control scheme for standardisation of measurement of antibodies to $H$ influenzae type $b$.

Approval for the trial was granted by the central Oxford research ethics committee.

Statistical analyses were performed using Epi Info version 5 . Analysis of variance was used for the comparison of response to vaccine batches and the Kruskal-Wallis test was used for comparisons of non-parametric data.

\section{Results}

All 107 infants tolerated immunisation for $H$ influenzae type $\mathrm{b}$ well and none failed to complete the study. A comparison of side effects can be seen in table 1 . Local reactions

Table 1 Number of infants with side effects after immunisation with $H$ influenzae type $b$ conjugate and diphtheria, pertussis, and tetanus vaccines $(n=107)$

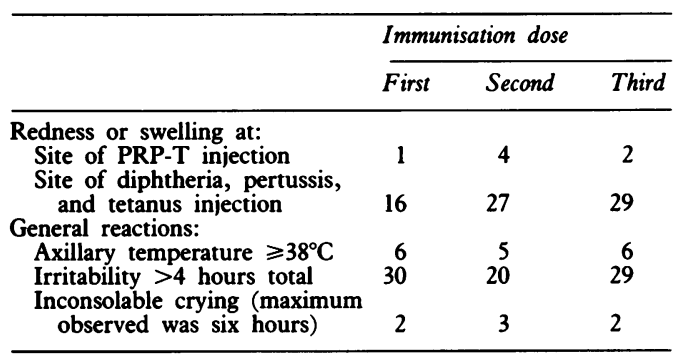

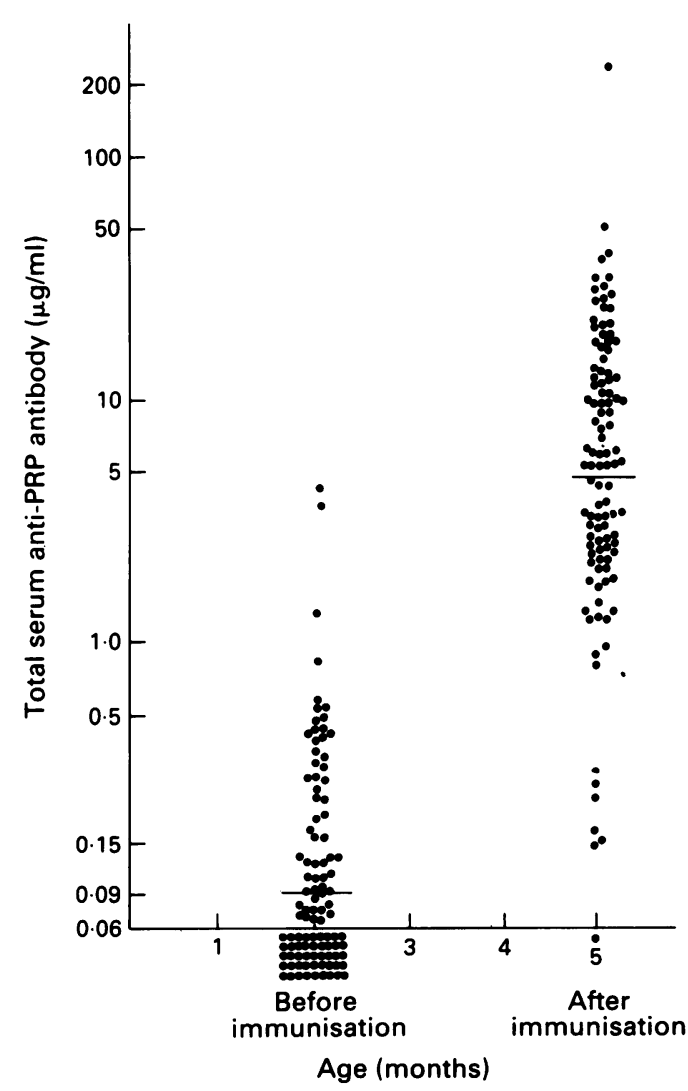

Concentration of serum antibodies specific for polyribosyl ribitol phosphate $(P R P)$ in infants immunised at 2,3 , and 4 months with PRP-T conjugate vaccine. Horizontal bars=geometric mean titres (Results less than the lower limit of sensitivity of the assay were assigned a value of 0.03 for calculation of the geometric mean titre.) 
(redness or swelling) were less common with PRP-T than with the diphtheria, pertussis, and tetanus vaccine. Systemic reaction rates were similar after each of the three primary immunisations. Two children had inconsolable crying and extensive local reactions to their first diphtheria, pertussis, and tetanus immunisations so pertussis was subsequently withheld. Their second and third immunisations were well tolerated.

Sufficient blood for analysis was obtained from 101 infants before immunisation and 107 infants after immunisation. The PRP-T vaccine was immunogenic, such that after the three dose course, 105 of the 107 children (98\%) had antibody concentrations consistent with protection $(\geqslant 0.15 \mu \mathrm{g} / \mathrm{ml})$ as determined by radioimmunoassays. Ninety seven children (91\%) had an antibody concentration of more than $1 \mu \mathrm{g} / \mathrm{ml}$. The geometric mean titre of antibody to PRP rose from $0.09 \mu \mathrm{g} / \mathrm{ml}$ at 8 weeks of age to $5.01 \mu \mathrm{g} / \mathrm{ml}$ at 20 weeks of age (figure).

IgG antibody concentrations measured by ELISA showed a good correlation with total antibody concentrations measured by radioimmunoassay $(r=0.864)$. By ELISA, only one child had a postimmunisation antibody concentration of $<0.16 \mu \mathrm{g} / \mathrm{ml}$ and $90 \%$ of children had an antibody concentration of $>1.0 \mu \mathrm{g} / \mathrm{ml}$ after immunisation.

All three batches of PRP-T vaccine elicited similar responses; analysis of variance showed no significant difference between batches in either the preimmunisation or postimmunisation antibody concentrations ( $p>0 \cdot 1$, table 2 ).

Among infants who had postimmunisation concentrations of $\geqslant 0.15 \mu \mathrm{g} / \mathrm{ml}$ by radioimmunoassay there were four who had less than fourfold rises in antibody concentrations. These all had anti-PRP antibody concentrations of $>0.15 \mu \mathrm{g} / \mathrm{ml}$ before immunisation. The effect of maternally derived anti-PRP antibodies on the serum antibody response to PRP-T was therefore evaluated. This was done by dividing infants into two groups according to preimmunisation antibody concentrations using $0 \cdot 15 \mu \mathrm{g} / \mathrm{ml}$ to divide the high and low antibody groups; postimmunisation antibody concentra-

Table 2 Geometric mean anti-PRP antibody titres for three batches of PRP-T, before and after immunisation $(\mu \mathrm{g} / \mathrm{ml})$

\begin{tabular}{lll}
\hline Vaccine batch & \multicolumn{2}{l}{ Geometric mean titre } \\
\cline { 2 - 3 } & Before & After \\
\hline S2141 & 0.08 & 4.61 \\
S2181 & 0.10 & $4 \cdot 12$ \\
S2189 & 0.09 & 6.44 \\
Overall & 0.09 & 5.01 \\
\hline
\end{tabular}

Table 3 Effect of maternally derived antibody on anti-PRP antibody responses evoked by $P R P-T$ given at 2, 3, and 4 months of age in 101 infants. (There was insufficient serum in six infants for analysis of antibody titres before immunisation)

\begin{tabular}{|c|c|c|}
\hline & Low group & High group \\
\hline $\begin{array}{l}\text { Maternally derived anti-PRP antibody concentration }(\mu \mathrm{g} / \mathrm{ml}) \\
\text { before immunisation } \\
\text { No of infants } \\
\text { Geometric mean anti-PRP antibody titre }(\mu \mathrm{g} / \mathrm{ml}) \text { : }\end{array}$ & $\begin{array}{l}<0 \cdot 15 \\
30\end{array}$ & $\geqslant 0 \cdot 15$ \\
\hline $\begin{array}{l}\text { Before immunisation } \\
\text { After immunisation }\end{array}$ & $\begin{array}{l}0.05 \\
4.66\end{array}$ & $\begin{array}{l}0 \cdot 40 \\
5 \cdot 81\end{array}$ \\
\hline
\end{tabular}

tions of the two groups were then compared. There was no significant differences (table 3 ; Kruskal-Wallis test, $\mathrm{p}>0 \cdot 1$ ). The antibody concentrations in the two infants not achieving $0 \cdot 15$ $\mu \mathrm{g} / \mathrm{ml}$ postimmunisation was also $<0 \cdot 15 \mu \mathrm{g} / \mathrm{ml}$ before immunisation.

\section{Discussion}

This study demonstrates that an accelerated three dose series of PRP-T immunisation, which is completed by 4 months of age, is both immunogenic and well tolerated. Local reactions were uncommon and the rate of general reactions was similar to that previously reported for UK children immunised with diphtheria, pertussis, tetanus vaccine alone or diphtheria, pertussis, tetanus and $H$ influenzae type b conjugate vaccine according to the 3,5 , and 9 months schedule. $^{1014}$

There was a good correlation between antibody concentrations measured by radioimmunoassay and by ELISA, the latter measuring only IgG antibodies. Similar findings have been reported previously, with total antibodies measured by both methods. ${ }^{15}$ These results show that ELISA can be used as an alternative to the classical radioimmunoassay for reliable measurement of PRP antibodies. The ELISA has other potentially valuable uses such as measurement of isotype specific antibodies and IgG subclass antibodies.

An inhibitory effect by placentally transferred antibodies was suggested in a previous immunogenicity study of a prototype PRP-tetanus toxoid conjugate vaccine. ${ }^{16}$ In contradiction, our study demonstrated that the immune response to PRP-T was not significantly affected by preimmunisation anti-PRP antibody concentrations.

The implementation of a new vaccine presents practical concerns, one of which is the present requirement to give $H$ influenzae type b immunisation by separate injection. This was not a significant problem in our study as demonstrated by the high level of recruitment $(75 \%)$ and the lack of dropouts. Preliminary observations from an implementation study now underway in the Oxford region suggests that vaccine uptake is minimally affected by the extra injection. However, studies are underway in which $H$ influenzae type $\mathrm{b}$ and diphtheria, pertussis, and tetanus immunisations are given in the one syringe; in Finland, it is part of normal clinical practice to do so.

Although the initial response of young infants to PRP-T vaccine is clearly effective, the longevity of the protection is an important question and affects whether booster doses are required. Studies in Finland of PRP vaccine suggest that a serum anti-PRP antibody concentration of at least $1 \mu \mathrm{g} / \mathrm{ml}$ correlates with long term protection. ${ }^{4}$ Given that over $90 \%$ of infants achieved antibody concentrations greater than 1 $\mu \mathrm{g} / \mathrm{ml}$, it is not certain that a booster dose will be required. In any case, it may be that the three dose course primes for a boostable (and thereby protective) response regardless of the absolute serum antibody concentration when the child is later exposed to $H$ influenzae type $\mathrm{b}$ 
organisms. ${ }^{17}$ This question may abe addressed by long term follow up of antibody concentrations and ideally by an efficacy trial with vaccinations given at 2,3 , and 4 months of age but without a booster dose in the second year of life.

Epidemiological surveillance in Oxford has shown that, of $H$ influenzae type b disease in children under 5 years, only $6 \%$ occurs in those under 4 months whereas $42 \%$ occurs before 12 months (unpublished data). This illustrates the rapid increase in risk of infection as maternally derived antibody declines. Given $95 \%$ vaccine uptake in the new 2, 3, and 4 month schedule, immunisation has the potential to prevent up to $90 \%$ of $H$ influenzae type b infections in young children. This translates to the potential annual prevention of 60 deaths and 1170 cases of infection in the UK. ${ }^{2}$ The encouraging immunogenicity and tolerability of PRP-T conjugate vaccine, demonstrated in this study, make it a candidate for inclusion in the routine national schedule. An open intervention study of PRP-T vaccine given at 2,3 , and 4 months of age is underway in the Oxford region. It is anticipated that 30000 infants will be immunised and that clinical efficacy can be evaluated by late 1992 when immunisation against $H$ influenzae type b disease is due to start in the national programme.

We are grateful to all the families who participated in the study and we are thankful for the support and materials provided by Dr J Roberts and Dr B Fritzell of Merieux UK and PasteurMerieux Serum et Vaccins respectively. We also thank Dr H Kayhty and Miss L Saarinen for performing the radioimmu
assays and Miss Emma Wills for typing the manuscript.

1 Ward J, Cochi S. Haemophilus influenzae vaccines. In: ard J, Cochi S. Haemophilus influenzae vaccines. In: Plotkin SA, Mortimer EA,

2 Tudor-Williams G, Frankland J, Isaacs D, et al. Haemophilus influenzae type b disease in the Oxford region. Arch Dis Child 1989;64:517-9.

3 Santosham M, Reid R, Ambrosino DM et al. Prevention of Haemophilus influenzae type $b$ infection in high risk infants treated with bacterial polysaccharide immune globulin. N Engl f Med 1987;317:923-9.

4 Peltola $\mathrm{H}$, Kayhty $\mathrm{H}$, Virtanen $M$, et al. Prevention of Haemophilus influenzae type $b$ bacteremic infections with the capsular polysaccharide vaccine. $N$ Engl $\mathcal{f} \mathrm{Med}$ 1984;310:1561-6.

5 Fothergill LD, Wright J. Influenzal meningitis: the relation of age incidence to the bactericidal power of blood against the causal organism. F Immunol 1933;24:273-84.

6 Avery OT, Geobel WF. Chemo-immunological studies on conjugated carbohydrate-proteins. II Immunological specificity of synthetic sugar-protein antigens. $\mathcal{F} \operatorname{Exp} M e d$ 1929;50:533-50.

7 Kayhty H, Eskola J, Peltola H, et al. Antibody responses to four Haemophilus influenzae type $b$ conjugate vaccines. Am f Dis Child 1991;145:146-9.

8 Decker MD, Edwards KM, Bradley R, Palmer P. Four conjugate Haemophilus influenzae b vaccines in infants: a conjugate Haemophilus influenzae $\mathrm{b}$ vaccines in infants: a comparative trial. Proceedings of the Interscience Conference
on Antimicrobial Agents and Chemotherapy. Atlanta, 1990: on Antimicr
abst 61 .

9 Immunisation Practices Advisory Committee. Haemophilus b conjugate vaccines for the prevention of Haemophilus influenzae type $b$ disease amongst infants and children two months of age and older. Recommendation of the Immunisation Practices Advisory Committee (ACIP). MMWR 1991;40:1-7.

10 Tudor-Williams G, Frankland J, Isaacs D, et al. Haemophilus influenzae type $b$ conjugate vaccine trial in Oxford: implications for the United Kingdom. Arch Dis Child 1989;64:520-4.

11 Farr RS. A quantitative immunochemical measure of the primary interaction between PBSA and antibody. $\mathcal{I}$ Infect Dis $1958 ; 103: 239-62$.

12 Kumararatne DS, Bignall A, Joyce $\mathrm{HJ}$, Hazelwood $M$. Antibody deficiency disorders. In: Gooi HC, Chapel $H$, eds. Clinical immunology: a practical approach. Oxford: IRL eds. Clinical immun

13 Gray BM. ELISA methodology for polysaccharide antigens: protein coupling of polysaccharides for adsorption to plastic tubes. F Immunol Methods 1979;28:187-92.

14 Pollock TM, Mortimer JY, Miller E, Smith G. Symptoms after primary immunisation with DPT and with DT vaccine. Lancet 1984;ii: 146-9.

15 Phipps DC, West J, Eby R, Koster M, Madore DV, Quataert SA. An ELISA employing a Haemophilus influenzae type $b$ oligosaccharide-human serum albumin conjugate correlates with the radioantigen binding assay. I Immunol Methods 1991;135:121-8.

16 Claesson BA, Schneerson R, Robbins JB, et al. Protective levels of serum antibodies stimulated in infants by two injections of Haemophilus influenzae type b capsular polysaccharide-tetanus toxoid conjugate. $\mathcal{F}$ Pediatr 1989 ; 114:97-100.

17 Granoff DM, Holmes SJ. Comparative immunogenicity of Haemophilus influenzae type b polysaccharide-protein conjugate vaccines. Vaccine $-1991 ; 9: \$ 30-4$. 